\title{
Integrated Thermal FE Analyses and Testing of Prototype Components for the ITER Bolometer Diagnostic
}

\author{
Harald Langer ${ }^{\mathrm{a}}$, Alexander Steinbicker ${ }^{\mathrm{a}}$, Hans Meister ${ }^{\mathrm{b}}$, Christoph Zauner ${ }^{\mathrm{a}}$ \\ ${ }^{a}$ KRP-Mechatec Engineering GbR, Garching b. München, Germany \\ ${ }^{b}$ Max-Planck-Institut für Plasmaphysik, Garching b. München, Germany
}

\begin{abstract}
The thermal design of diagnostic components for the ITER bolometer diagnostic is of critical importance with respect to survivability, reliability and performance. To support the development of bolometer camera prototypes for ITER, KRP-M has performed the thermal analysis to determine the temperature distribution, to identify critical items and uncertainties, and to optimize the camera design to achieve low detector temperatures. The analysis has been carried out in close interaction with tests for reducing the uncertainties of those parameters responsible for the highest variations in the results and for verifying the simulation model. Special tests have been designed and performed by KRP-M for determining emissivity and thermal contact conductivity parameters. For a prototype of the bolometer camera, a thermal balance test has been designed and used to verify the FE model.
\end{abstract}

Keywords: thermal analysis, in vessel components, experimental verification, thermal contact conductivity, bolometer camera, ITER diagnostics

\section{Introduction}

Supporting the development of bolometer camera prototypes for ITER [1] within a nationally funded project, KRP-M has performed the thermal analysis to determine the temperature distribution, to identify critical items and uncertainties, and to optimize the camera design to achieve low detector temperatures. The major objectives of the thermal analysis and thermal design optimization have been to:

- minimize temperature gradient across the detector chip, preferable $<1^{\circ} \mathrm{C}$

- minimize temperature level of detector, preferably $<200^{\circ} \mathrm{C}$

- $\quad$ assure all temperature levels are lower than respective material limits

\section{FEM Analysis}

\subsection{Model Description}

For the thermal simulation, a model of the bolometer camera has been established in the FEM program ANSYS based on the initial CAD design. The model has been established as solid model using SOLID90/87 elements (Fig. 1). Radiation has been implemented by the Radiosity Solver within ANSYS.

\subsection{Loads and Boundary Conditions}

The camera is subject to two kinds of thermal loads, thermal flux (HF) on outer surfaces by plasma radiation through gaps in blanket modules (Fig. 1) and nuclear heating acting as volume load. Based on the assessment of the thermal loads for all proposed camera positions, a camera behind the inner target of the divertor has been chosen for this analysis as it is representative for the highest thermal loads [2] [3]. The thermal input load totals to $817 \mathrm{~W}$ (51W total heat flux load, $766 \mathrm{~W}$ total nuclear heating load).

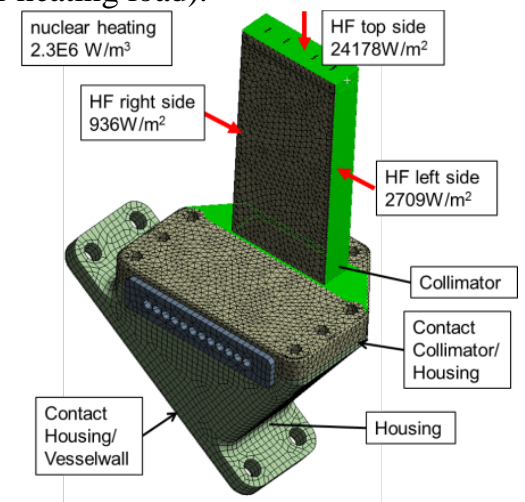

Fig. 1. FEM model of bolometer camera.

Referring to outer boundary conditions, a temperature of the supporting structures of $150^{\circ} \mathrm{C}$ has been assumed (actively cooled) and an ambient temperature of the surrounding structures of also $150^{\circ} \mathrm{C}$. The emissivity for the outer camera surfaces (Titanium-Zirconium-Molybdenum alloy (TZM)) was set to 0.38 . This value has been determined and optimized w.r.t. machining parameters by an experimental campaign (see section 3.1). Another, even more important parameter for the resulting detector temperature is the thermal contact conductivity (TCC) for the various bolted contacts of the camera (collimator/housing, housing/vessel wall. Based on previous experience [4], a preliminary value of $2000 \mathrm{~W} / \mathrm{m}^{2} \mathrm{~K}$ has been assumed for the analysis. However, because of this parameter having the highest impact on the resulting temperature distribution, an experimental campaign has been performed to investigate and verify it (see section 3.2). 


\subsection{Design optimization}

The basic rationale for the design optimization in order to reduce temperatures in the sensor area has been to separate the heat flow caused by the outer heat flux load from the sensor region (Fig. 2). As the outer heat flux load is highly asymmetric, this separation helps to reduce temperature gradients across the sensor chip, too. Also for reducing the temperature gradient across the chip, the design of the sensor support has been modified to achieve a homogeneous heat flow path from the chip to the vessel wall heat sink.

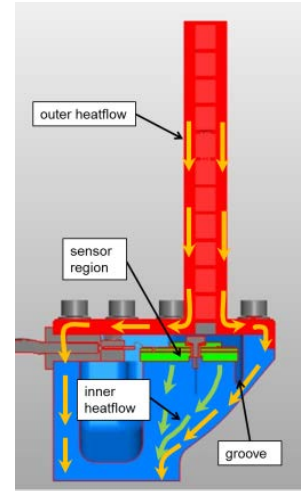

Fig. 2. Heat flow path optimization.

\subsection{FEM Results}

The maximum temperature is $486^{\circ} \mathrm{C}$ at the top of the collimator (Fig. 3). The observed temperature levels are not critical for the applied materials. The temperature level in the sensor region is significantly above the target level of $200^{\circ} \mathrm{C}$ (Fig. 4).

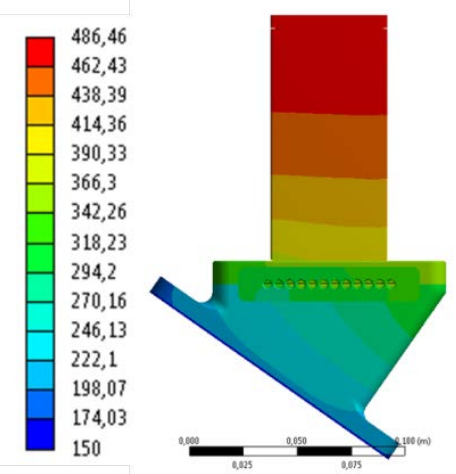

Fig. 3. Temperature results for camera.

The maximum overall temperature gradient across the chip $\left(3.1^{\circ} \mathrm{C}\right.$ diagonally) is also above the target level of $1^{\circ} \mathrm{C}$. However, the technically relevant gradient between each respective measurement and reference absorber in transverse direction is below $1^{\circ} \mathrm{C}$, so the gradient goal has been considered as achieved. Furthermore, this design achieved to dissipate completely passively a total heat load of $817 \mathrm{~W}$.

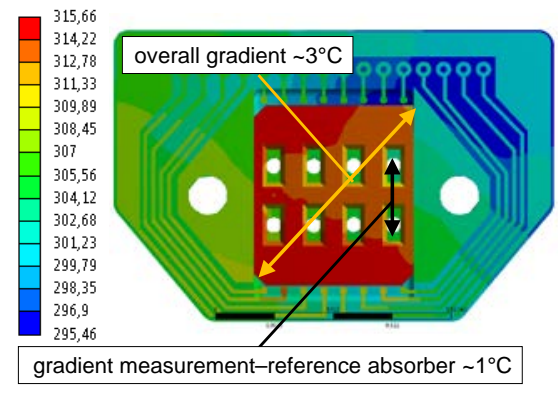

Fig. 4. Temperature results for sensor chip.

\subsection{Sensitivity Study}

The results for the thermal analysis depend on assumptions made on various parameters, of which some are known only with considerable uncertainty. A sensitivity study performed within the scope of the FEM analyses show that the most important ones are the emissivity (heat sink via radiation) and TCC (heat sink via contact to vessel wall and internal heat flow). They significantly determine the temperature levels in the camera.

For the investigated emissivity range of 0.1 to 1 (Fig. 5, left), the heat loss via radiation varies by more than $50 \%$. An even more significant influence on sensor temperature level has the TCC of the housing/vessel wall connection (Fig. 5, right). For TCC $=1000 \mathrm{~W} / \mathrm{m}^{2} \mathrm{~K}$, the chip temperature increases by almost $50^{\circ} \mathrm{C}$. In order to achieve a high confidence in the thermal analysis results, experimental campaigns have been performed to verify these parameters (section 3 ).
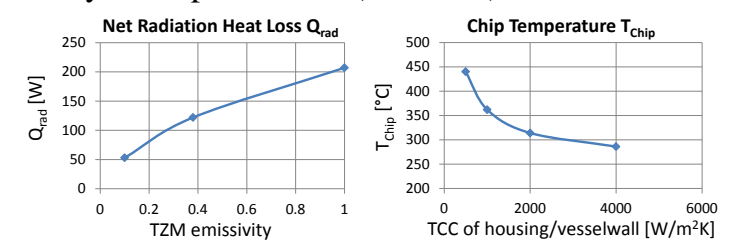

Fig. 5. Sensitivity study results (left: emissivity / heat loss via radiation; right: chip temperature TCC $_{\text {housing/vessel wall). }}$.

\section{Experimental Investigations}

\subsection{Emissivity}

The emissivity of TZM (material of outer camera body) has been investigated in dependency of various surface treatments, ranging from turning, milling, polishing to sandblasting with different media. The experiments have been performed using small disc samples $(\varnothing=20 \mathrm{~mm}$, Table 1$)$ and a DB100 reflectometer. In Table 1 , the results are listed. In order to achieve a maximum heat loss via radiation, sandblasting has been selected as surface treatment for the outer camera surfaces and an emissivity of 0.38 has subsequently been applied in the thermal analysis. 
Table 1. Emissivity of TZM.

\begin{tabular}{|l|l|c|c|}
\hline \multirow{3}{*}{} & Surface Preparation & \multicolumn{2}{|c|}{$\begin{array}{c}\text { Total hemispheric } \\
\text { emissivity* eH }\end{array}$} \\
\cline { 2 - 4 } & avg. & std. \\
\cline { 2 - 4 } & milling (roughing) & 0.19 & 0.02 \\
\cline { 2 - 4 } & milling (finishing, reference) & 0.19 & 0.01 \\
\hline turning & 0.15 & 0.03 \\
\hline & milling + sandblasting (alu. oxide) & 0.38 & 0.01 \\
\hline & milling + electropolishing & 0.07 & 0.01 \\
\hline & turning + sandblasting (glass beads) & 0.16 & 0.02 \\
\hline
\end{tabular}

\subsection{Thermal Contact Conductance}

For determining the thermal contact conductivity (TCC), a special set-up has been designed (Fig. 6), which allows the determination of TCC in dependence of contact pressure.

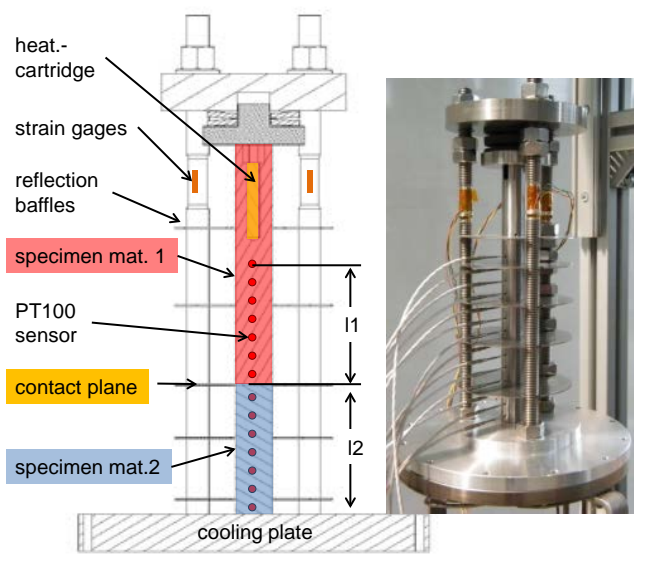

Fig. 6. TCC measurement set-up.

The test setup consists of the two cylindrical specimens pressed onto each other by means of a disc spring loaded frame. A heat flow is imposed through the specimens by heating the top of the upper one by an embedded heating cartridge and cooling the bottom of the lower one by an actively cooled plate. The temperature profile along the specimens is measured by distributed PT100 sensors. The complete set up is installed in a vacuum chamber to exclude convection heat transfer. The TCC is determined by deriving the heat flow rate $\mathrm{Q}$ and the temperature difference across the contact $(\Delta T C)$ from the distributed temperature measurements (Fig. 7). The tests have been performed for the material combinations present in the bolometer camera (TZM/TZM, TZM/Stainless Steel, TZM/Aluminum Nitride).

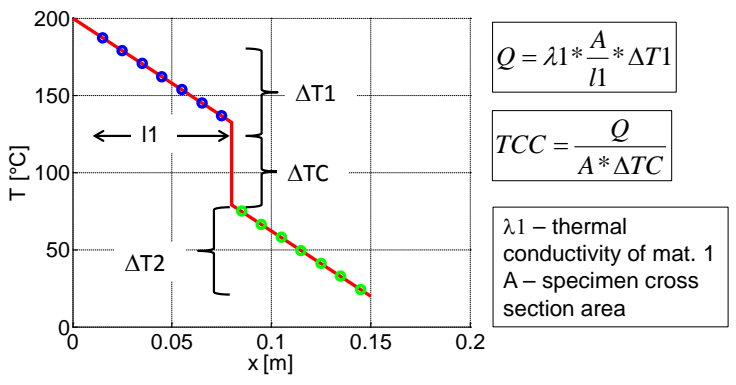

Fig. 7. Determination of TCC from temperature measurements along the specimens.
The results are illustrated in Fig. 8. The TCC is highly dependent on contact pressure. E.g. for TZM/TZM contact, values of 1600 to $20000 \mathrm{~W} / \mathrm{m}^{2} \mathrm{~K}$ have been determined for contact pressures from 1 to $30 \mathrm{MPa}$ and typical surface finishing. Given an average contact pressure for the Collimator/Housing (TZM/TZM) connection of 2530MPa (assuming homogeneous pressure by bolt pretension, 9 M6 TZM bolts, 7Nm torque), a TCC above $15000 \mathrm{~W} / \mathrm{m}^{2} \mathrm{~K}$ can be expected. Thus the FEM assumption of $2000 \mathrm{~W} / \mathrm{m}^{2} \mathrm{~K}$ would be very conservative. For the housing/vessel wall (TZM/SS) connection with an estimated average contact pressure of $8 \mathrm{MPa}$ (again, estimated from bolt pretension, 4 M8 A4-70 bolts, $16 \mathrm{Nm}$ torque), a TCC of $4000 \mathrm{~W} / \mathrm{m}^{2} \mathrm{~K}$ can be expected. However, as the housing is connected by only 4 bolts, the actual contact pressure varies strongly along the contact surface, thus leading to a lower effective TCC value.

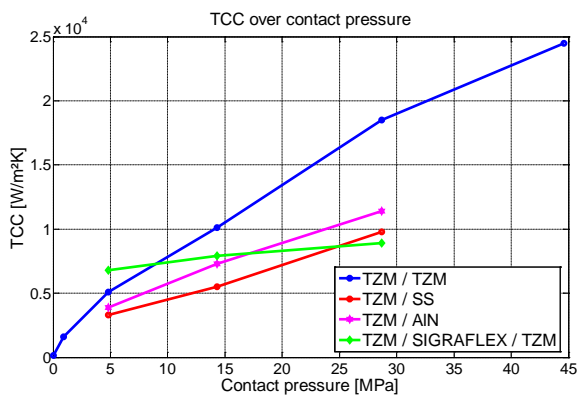

Fig. 8. TCC results for the different material combinations of the camera in dependence of contact pressure.

\subsection{FE Model Verification}

For the verification of the complete FE model, a thermal balance test with a prototype has been designed and performed. The test set-up is illustrated in Fig. 9. A heat flow has been imposed by cartridge heaters to the top of the collimator. The contact to the vessel wall is simulated by a representative Stainless Steel dummy, which is mounted to a cooling plate. Again, the set-up is installed in a vacuum chamber.

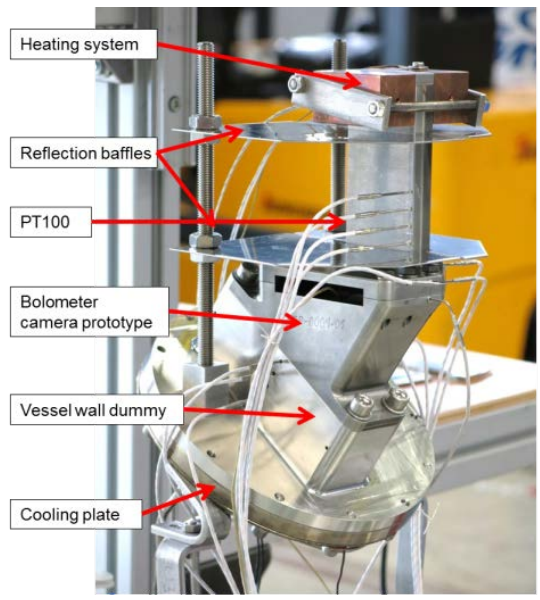

Fig. 9. Test set-up for thermal balance test of Bolometer camera prototype. 
The temperatures in the camera are measured at various locations using PT100 temperature sensors. The heat flow through the collimator and the vessel wall dummy are determined by distributed temperature measurements similar to the TCC tests. For the correlation with the FE model, TCC and emissivity values have been used as main parameters for the model matching process.
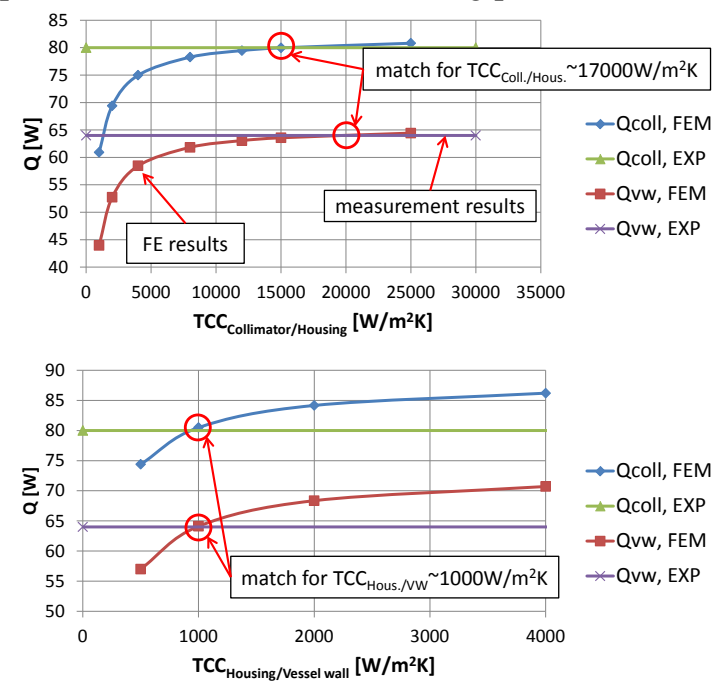

Fig. 10. Matching of heat flow rates Q (FEM vs. Test) in collimator and vessel wall dummy by varying TCC of collimator/housing and housing/vessel wall connection.

In Fig. 10, the heat flow rates for collimator $\mathrm{Q}_{\text {coll }}$ and vessel wall dummy $\mathrm{Q}_{\mathrm{vw}}$ as obtained from the FE model for various values of the TCC $_{\text {collimator/housing (upper graph) and TCC }}$ housing/vessel wall (lower graph) are shown together with the experimentally determined value (horizontal lines). It can be seen that a good agreement is achieved for

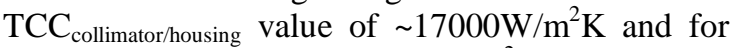

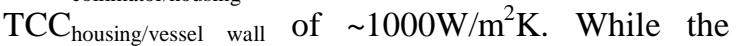

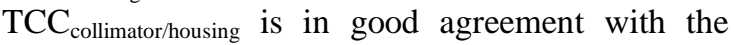
expectations from TCC experiments for $\mathrm{TZM} / \mathrm{TZM}$, the $\mathrm{TCC}_{\text {housing/vessel wall }}$ is significantly below the expectations from TCC experiments $\left(4000 \mathrm{~W} / \mathrm{m}^{2} \mathrm{~K}\right)$. The reason is that only 4 bolts are used for the connection which leads to a very low contact pressure in the middle region and thus to a low effective TCC. Thus, this connection should be redesigned.

Applying these TCC values in the FE model, a very good correlation between the FE temperature results and the measurements is achieved having a maximum deviation of $2.7^{\circ} \mathrm{C}$ (Table 2) and thus validating the model very well.

\section{Resume}

The thermal analysis of the Bolometer camera has shown that the current conceptual design is capable of surviving operational thermal loads in ITER as passively cooled structure. However, the temperature level for the sensor is above the desired level and shows the need for further design modification or an active cooling.

Table 2. Comparison of temperatures from FE analysis and experiment.

\begin{tabular}{|c|c|c|c|c|}
\hline \multirow{2}{*}{$\begin{array}{l}\text { Temperature } \\
\text { sensor }\end{array}$} & \multirow{2}{*}{ Measurement position } & \multicolumn{3}{|c|}{ Temperature $\left[{ }^{\circ} \mathrm{C}\right]$} \\
\hline & & Test & FEA & $\Delta T$ \\
\hline Temp_1 & \multirow{3}{*}{ Collimator } & 205.8 & 205.8 & 0 \\
\hline Temp_2 & & 193.7 & 193.8 & 0.1 \\
\hline Temp_3 & & 181.3 & 181.9 & 0.6 \\
\hline Temp_5 & \multirow{4}{*}{$\begin{array}{l}\text { Contact collimator / } \\
\text { housing }\end{array}$} & 137.7 & 137.4 & -0.3 \\
\hline Temp_6 & & 135.4 & 134.8 & -0.6 \\
\hline Temp_7 & & 143.6 & 144.8 & 1.2 \\
\hline Temp_8 & & 140.1 & 139.8 & -0.3 \\
\hline Temp_9 & \multirow{3}{*}{$\begin{array}{c}\text { Contact camera / vessel } \\
\text { wall dummy }\end{array}$} & 120.4 & 119.1 & -1.3 \\
\hline Temp_10 & & 119.7 & 118.7 & -1 \\
\hline Temp_11 & & 105.8 & 104.6 & -1.2 \\
\hline Temp_12 & Vessel wall dummy & 97.4 & 97.4 & 0 \\
\hline Temp_chip & Detector chip mounting & 125.4 & 128.1 & 2.7 \\
\hline
\end{tabular}

For the achievement of reliable FE results for the thermal analysis of the bolometer cameras, it has been important to investigate critical parameters by sensitivity analysis and to verify these parameters experimentally. The emissivity and the TCC towards the vessel wall have been identified as important parameters. The performed experiments have established a good basis for emissivity values as well as TZM/TZM and TZM/stainless steel TCC values in dependence of contact pressure.

The thermal balance test of the bolometer camera has validated the FE models applied and highlighted the critical importance of the thermal contact to the vessel wall. The results show the need for an improved design achieving higher thermal contact conductivity.

\section{Acknowledgement}

This work was performed by funds from the German Ministry for Education and Research under the Grant No. 03FUS0006. The sole responsibility for the content presented lies with the authors.

\section{References}

[1] H. Meister, L. Giannone, L. D. Horton, G. Raupp, W. Zeidner, G. Grunda, S. Kalvin, U. Fischer, R. Reichle, A. Serikov and S. Stickel, The ITER bolometer diagnostic - status and plans, Review of Scientific Instruments, vol. 79, 10F511, 2008.

[2] A. Suarez, R. Reichle, M. Loughlin, E. Polunovskiy and $\mathrm{M}$. Walsh, Neutronic analysis for bolometers in ITER, Fusion Engineering and Design, vol. 88, pp. 1395-1399, 2013.

[3] S. Kalvin and G. Grunda, Diagnostic design for ITER: Optimisation of the ITER bolometer linesof-sight, performance analysis and engineering and design activities, Association EURATOM-HAS, 2008.

[4] H. Greuner, B. Böswirth, J. Boscary, G. Hofmann, B. Mendelevitch, H. Renner and R. Rieck, Final design of W7-X divertor plasma facing components - tests and thermo-mechanical analysis of baffle prototypes, Fusion Engineering and Design, vol. 66-68, pp. 447-452, 2003. 